\title{
Gamificando no Ensino da Contabilidade: Uma prática com o jogo Deborah
}

\author{
Gabriela Cunha de Oliveira ${ }^{1}$ \\ ${ }^{1}$ União Educacional do Norte (UNINORTE) Faculdade Barão do Rio Branco (FAB) \\ CEP 69.915-901 - Rio Branco- AC, Brasil \\ gabriela.oliveiraduninorteac.edu.br
}

\begin{abstract}
Resumo. Este trabalho teve como objetivo apresentar uma prática de gamificação utilizando o jogo Deborah (Double Entry Bookeeping or Accounting History) com a finalidade de promover o engajamento de 64 alunos na disciplina Teoria da Contabilidade em um curso de graduação em ciências contábeis. Resultou- se que embora os alunos inicialmente sentiram dificuldades em avançar as etapas do jogo, consideraram- o como uma ferramenta auxiliar (67,7\%) e determinante (33,3\%) no aprendizado da disciplina e na evolução histórica da contabilidade.
\end{abstract}

\begin{abstract}
This work aimed to present a gamification practice using the Deborah game (Double Entry Bookeeping or Accounting History) with the purpose of promoting the engagement of 64 students in the subject of Accounting Theory in an undergraduate course in accounting sciences. It was found that although the students initially felt difficulties in advancing the stages of the game, they considered it as an auxiliary tool (67.7\%) and determinant (33.3\%) in the learning of the discipline and in the historical evolution of accounting.
\end{abstract}

\section{Introdução}

A Gamificação na educação apresenta- se como uma ferramenta pedagógica que visa promover a participação ativa e engajamento de alunos no processo de ensinoaprendizagem. Estudos têm sido realizados a fim de dar visibilidade a essa modalidade de metodologia ativa em que os alunos podem se tornar aprendizes engajados e motivados em aprender [Freitas et al 2016].

Experiências com a criação de jogos para desenvolver competências [Alves, Hostins e Raabe 2017], a utilização de um game relacionado à uma disciplina [Mioto et al. 2017] ou até mesmo a utilização de elementos de um jogo visando cativar os alunos para determinado assunto [Freitas et al. 2016] são possibilidades de gamificar no processo educativo, tanto no ensino básico quando no ensino superior.

O estudo dessas experiências no ensino superior tem tido bons resultados a exemplo de [Toda et al. 2016] que propuseram um método para gamificar no ensino das Ciências Biológicas e resultou- se que o método foi considerado divertido, interessante e engajador e [Lemos et al. 2017] que ao propor a utilização de um game no ensino de anatomia humana no curso de enfermagem, observaram a união entre a eficiência do jogo como uma tecnologia educacional e o aprendizado dos alunos.

Diante disso e da relevância em explorar ainda mais tal tema em outros cursos do ensino superior, o presente trabalho tem o objetivo de apresentar uma prática pedagógica 
VII Congresso Brasileiro de Informática na Educação (CBIE 2018)

Anais dos Workshops do VII Congresso Brasileiro de Informática na Educação (WCBIE 2018)

na qual utilizou- se um jogo para engajar e motivar alunos em uma disciplina do curso de graduação em Ciências Contábeis.

\section{O jogo Deborah}

Deborah- é um jogo criado no âmbito da Faculdade de Economia, Administração e Contabilidade da Universidade de São Paulo (FEA-USP) com o objetivo de propor um ensino inovador e lúdico acerca da história da Contabilidade. O jogo é formado por 4 fases onde cada uma representa período de tempo da evolução histórica da ciência contábil.

$\mathrm{Na}$ primeira fase intitulada "história antiga da contabilidade" o jogador é desafiado a contabilizar como os antigos contabilizavam utilizando os desenhos que representavam a quantidade os itens do patrimônio (animais, alimentos etc). Na segunda fase chamada de "história medieval da contabilidade" o jogador precisa encontrar em um cenário da era medieval os elementos que contribuíram para a origem das partidas dobradas- principal técnica de contabilização do patrimônio. Já na terceira fase o jogador descobre e escolhe os livros contábeis específicos para cada tipo de contabilização em um cenário da "história moderna da contabilidade" e a quarta e última fase, a "história contemporânea" o jogador precisa superar obstáculos e encontrar os elementos presentes na atualidade da profissão Contábil.

Considerando que a disciplina Teoria da Contabilidade tem como ementa a evolução histórica da contabilidade, onde se estuda os aspectos históricos e científicos do reconhecimento da Contabilidade como Ciência, propôs- se uma prática de gamificação utilizando tal jogo.

\section{Métodos}

A prática deu- se pela proposta de 64 alunos do curso de Ciências Contábeis jogarem o Deborah como atividade da disciplina de Teoria da Contabilidade em uma instituição de ensino superior na cidade de Rio Branco- Acre.

A prática foi dividida em 3 fases: na primeira os alunos tiveram uma aula expositiva na qual expôs- se teoricamente a evolução contábil; na segunda, os alunos foram levados ao laboratório de informática e tiveram 4 horas para explorar e jogar as quatro fases do jogo e a terceira foi realizada uma avaliação com questionário de múltipla escolha ao fim do semestre visando a percepção dos discentes quanto à prática utilizada na disciplina.

O questionário foi produzido e divulgado em meio digital na plataforma "Google Forms" contendo as seguintes perguntas: "O que você achou da disciplina de Teoria da Contabilidade?", "Você jogou o jogo Deborah?", "Quais fases você conseguiu jogar?”; "O que achou da ideia de jogar um jogo como atividade na disciplina"?, "O que foi melhor na disciplina"? e "O que foi pior na disciplina”? 
VII Congresso Brasileiro de Informática na Educação (CBIE 2018)

Anais dos Workshops do VII Congresso Brasileiro de Informática na Educação (WCBIE 2018)

\section{Resultados e Discussões}

Ao anunciar a prática já pôde observar que os alunos ficaram interessados e curiosos para realizar tal atividade, haja vista que quando se fala em teoria para alunos de Contabilidade, o comum é que os mesmos achem a matéria chata ou até mesmo irrelevante, mesmo já tendo o conhecimento de que a Contabilidade não é uma ciência exata e sim uma ciência social aplicada. Assim, propor algo diferente despertou uma motivação para estudar a disciplina.

$\mathrm{Na}$ prática com o jogo (Figura 1), em cada fase os participantes inicialmente sentiam dificuldades em cumprir as tarefas do game, mas nas tentativas em ultrapassar as fases observou-se os participantes motivados tanto por perceber o aprendizado do conhecimento da evolução contábil quanto por conseguir vencer os desafios e fases do jogo. (Figura 2). Comentários dos participantes como "esse jogo é muito interessante", "só vou embora quando conseguir passar dessa fase", "nossa, que legal professora" simbolizam essa motivação observada.

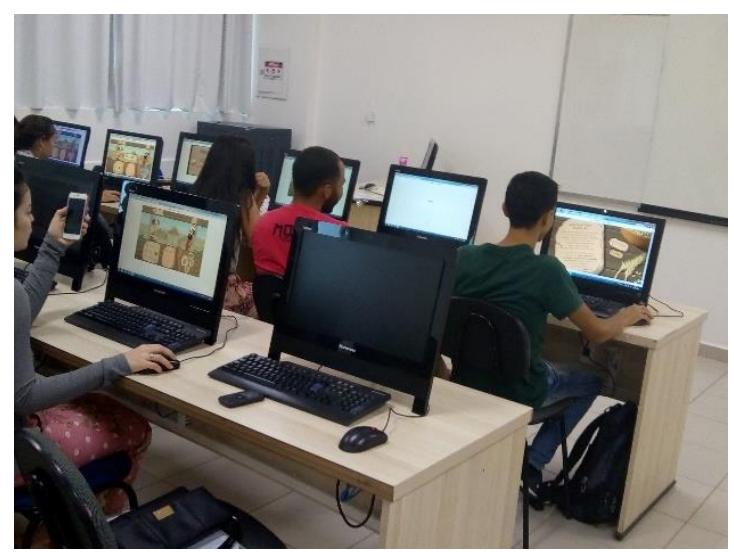

Figura 1: alunos explorando o Deborah

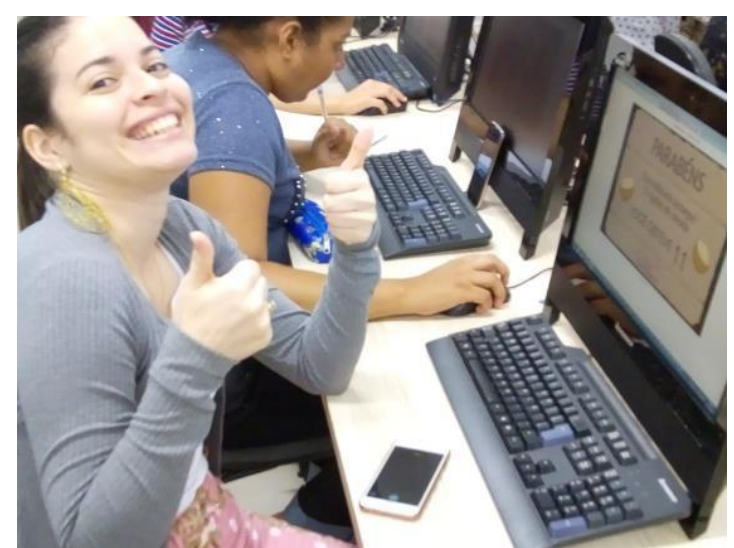

Figura 2. Aluna comemorando vitória da primeira fase do jogo 
Os resultados da avaliação pelos alunos acerca da disciplina e a prática com o game foi que a maioria $(66,7 \%)$ consideraram a disciplina como "Boa" em uma escala entre "Muito Ruim e Ótima", $100 \%$ dos alunos jogaram o game, sendo que a fase mais explorada foi a História antiga da Contabilidade (66,7\%). Além disso, 67,7\% dos participantes acharam a ideia de jogar um jogo como atividade na disciplina foi uma boa ferramenta para auxiliar o aprendizado da história da Contabilidade e 33,3\% consideraram que o jogo foi não apenas auxiliar, mas determinante no seu aprendizado. Os quesitos considerados como o melhor na disciplina foram as atividades realizadas em sala de aula $(55,6 \%)$, que inclui a prática do jogo e a didática da professora $(33,3 \%)$ e quesito considerado pior na disciplina foram as aulas expositivas $(75 \%)$.

\section{Conclusão}

Concluiu- se que, embora os alunos de Ciências Contábeis ainda sintam que estudar o aspecto teórico de científico da Contabilidade é irrelevante, há maneiras de despertar o interesse e engajamento nos mesmos, pela existência de um jogo criado especificamente para se trabalhar na disciplina e a possibilidade de os alunos perceberem o apreensão da matéria e se motivarem para aprender mais à medida que vão vencendo as etapas do jogo.

\section{Referências}

Alves, A. G; Hostins, R.C.L; Raabe, A.L (2017). "Eu fiz meu game": um framework para desenvolvimento de jogos por crianças. Em: Anais dos Workshops do IV Congresso Brasileiro de Informática na Educação (WCBIE 2017). DOI: 10.5753/ cbie.wie.2017.2.

Freitas, A.A; Lima,T; Canedo.E.D; Costa, R.L. (2016) Pesquisa-Ação: Uma metodologia do "Conhecer" e do "Agir" coletivo. Sociedade em debate, Pelotas, 7 (2): 5-25, Agosto/ 2001. Disponível em:<

http://revistas.ucpel.tche.br/index.php/rsd/article/viewFile/570/510>. Acesso em: 08/02/2017.

Mioto, J.A; Batista, E.J.S; Santos, Q de A; Bogarim, C.A.C; Lima.A.C (2017). As aventuras de calculino: jogo para ensino de raciocínio lógico. Em: Anais dos Workshops do VI Congresso Brasileiro de Informática na Educação (WCBIE 2017). DOI: $10.5753 /$ cbie.wie. 2017.451.

Toda, A.M; Silva, Y.R.O; Cruz, W; Xavier, L; Isotani, S (2016). Um processo de Gamificação para o ensino superior: Experiências em um módulo de Bioquímica. Em: Anais dos Workshops do V Congresso Brasileiro de Informática na Educação (WCBIE 2016). DOI: 10.5753/cbie.wie.2016.495

Lemos, W.D; Junior, I.H.F; Filho, A.S.C (2017). Uma proposta de um Serius Game no Auxílio do Aprendizado da Anatomia Humana. Em Anais do VI Congresso Brasileiro de Informática na Educação (SBIE 2017). DOI: 10.5753/cbie.sbie.2017.655 